\title{
REPRESENTAÇÃO MIDIÁTICA, LINGUAGEM E MOVIMENTOS SOCIOCULTURAIS: PATRIMÔNIO, MEMÓRIA E IDENTIDADE ${ }^{1}$
}

PESSOA, Marcelo²

\section{DOI NUMBER: http://dx.doi.org/10.33726/akedia2447-7656v6a52018p47-61}

RESUMO: O presente texto, por meio de uma revisão bibliográfica, traz uma discussão sobre a relação entre manifestações sociais, culturais e os demais grupos organizados da sociedade civil que ajudaram a propor, no Brasil, definições parciais e em fluxo contínuo quanto à identidade cultural desta llha de Vera Cruz. A partir de argumentos da crítica pós-colonial, estética e sociológica, apontamos para direções em que as atividades socioculturais brasileiras, desde o período colonial, reservam e revelam muito do patrimônio histórico e social do povo que somos ou que ainda queremos ser. Como resultado deste ensaio, longe de descrever verdades, anunciam-se desafios, diante dos quais cada pesquisador que com nossa escrita se deparar, poderá se deter, na medida de sua coragem intelectual e na dimensão de abrangência de suas respectivas linhas de pesquisa.

PALAVRAS-CHAVE: Identidade, Cultura Brasileira, Linguagem, Representação Midiática.

ABSTRACT: The present text, through a bibliographical revision, presents a discussion on the relationship between social, cultural manifestations and other organized groups of civil society who helped propose, in Brazil, partial definitions and streaming as the identity this cultural Island of Vera Cruz. Thinking from the postcolonial critique, aesthetics and sociological, aim for directions in which the Brazilian social and cultural activities, since the colonial period, reserve and reveal much historical and social heritage of the people who we are or who we want to be still. As a result of this essay, far from describing truths, announces challenges, in front of which each researcher who with our writing come across, you can pause, the extent of your intellectual courage and breadth dimension of their respective research lines.

KEYWORDS: Brazilian Identity, Culture, Language, Media Representation.

\footnotetext{
${ }^{1} \mathrm{O}$ presente texto investiga traços de nossa identidade sociocultural e, devido a isso, dialoga com temáticas e vieses teóricos discutidos noutro Artigo nosso, intitulado "Tropicalismo, arte, sociedade: compreensões ainda úteis para uma educação que se deseje plural", publicado pela Revista SCIAS / COED Arte e Educação, v. 02, p. 02-16, 2014. Neste sentido, ainda que lá houvéssemos tratado de questões entrecruzadas entre o Tropicalismo e a Educação Brasileira, ao revisitar meus próprios escritos, me surpreendo, não raramente, em ver o quanto sou repetitivo em minhas postulações. Portanto, mea culpa, mea maxima culpa! E, àqueles que nos leem com certo hábito - se é que estes existem -, informo que semelhanças entre este e aquele texto, não são meras coincidências, mas frutos de minha incompetência em realizar descobertas que possam lhes ser mais úteis - sorry!

2 Sociolinguísta, docente da UEMG, Unidade Frutal, com Doutorado em Letras pela UEL e Pósdoutorado em Divulgação Científica pela USP.
} 


\section{INTRODUÇÃO}

\section{Várias correntes artísticas ou ativistas brasileiras acabaram} incorporando, meio que sem querer, o mérito positivo ou a culpa negativa de fazer transparecer por meio de seus manifestos e postulações parte da face cultural e consequentemente identitária que, ao longo de muito tempo, tem ajudado a definir o Brasil e ao seu povo (CHAUÍ, 2017) ${ }^{3}$.

Indo diretamente ao assunto, portanto, vemos que se os integrantes de movimentos socioculturais de ontem e de hoje como a Antropofagia Oswaldiana $^{4}$ (1928), o Cinema Novo ${ }^{5}$ (1955), a Poesia Concreta ${ }^{6}$ (1955), a Bossa Nova ${ }^{7}$ (1958), o Tropicalismo ${ }^{8}$ (1967), a Passeata do Cem Mil $^{9}$, o Movimento das Diretas-Já ${ }^{10}$ (1983-1984), o MST ${ }^{11}$ (1984), os Caras-Pintadas ${ }^{12}$

\footnotetext{
3 Para entender o vocábulo "povo", recorremos para este texto à definição de Marilena Chauí, em sua obra "Conformismo e Resistência", de 1986, republicada em 2017. De Chaú, nos apropriamos, entre outras definições da autora, daquela que entende o povo como generalidade, como instância jurídicopolítica (dotada dos critérios do racionalismo da Ilustração) e como particularidade social: os "pobres". De um lado desse entendimento, portanto, tem-se que ao povo, entendido como generalidade política, cabe a tarefa política e racional de fundação e de sustentáculo dos preceitos e ordenamentos sociais. De outro lado, temos o povo como particularidade social e, a esse "povinho" e suas necessidades básicas, diznos Chauí, "cabe auxiliá-lo através da filantropia e educá-lo através da disciplina do trabalho industrial, educação essencial para conter suas paixões obscuras, supersticiosas, sua irracionalidade e, sobretudo sua inveja, que se exprime no desejo sedicioso do igualitarismo" (CHAUÍ, 1986, p. 17 e 2017, p. 22).

${ }^{4}$ Tomamos por princípio do movimento, a data de publicação do Manifesto Antropófago, na Revista de Antropofagia, assinado por Oswald de Andrade.

${ }_{5}^{5}$ Preferimos como nascimento do movimento, a data do filme "Rio 40 Graus", de Nelson Pereira dos Santos.

${ }^{6}$ Adotamos por começo do movimento o $\mathrm{n}^{\circ}$ 2, da "Revista Noigandres", em que Augusto de Campos nomeia o que conhecemos hoje por concretismo.

${ }^{7}$ Considera-se aqui, como marco inicial do movimento, o disco lançado por João Gilberto, contendo as canções "Chega de Saudade", e "Bim Bom".

${ }^{8}$ Ano do III Festival de Música Popular Brasileira da Record, considerado pela crítica como um típico "festival tropicalista". Tem-se, então, o Movimento Tropicalista, o Tropicalismo, ou simplesmente, a Tropicália.

${ }^{9}$ Organizada no Rio de Janeiro pelo movimento estudantil, esta passeata contra a Ditadura Militar, em junho de 1968, reuniu nomes que hoje soam como improváveis sob um mesmo teto, tais como Caetano Veloso, Grande Otelo, Cacá Diegues, Chico Buarque, Clarice Lispector, Fernando Gabeira, José Dirceu, Marieta Severo, Orestes Quércia, Tancredo Neves, Gilberto Gil e Milton Nascimento etc. - assim mesmo, tudo junto e misturado.

${ }^{10}$ Entre os anos de 1983 e 1984, esse movimento mobilizou a sociedade civil pela realização de eleições diretas, o que, de certo modo, ao mesmo tempo em que aconteceu foi frustrado, isso devido à eleição e conseguinte morte de Tancredo Neves.

${ }^{11}$ Ano em que, numa reunião no Paraná, com a Comissão Pastoral da Terra, decidiu-se pela fundação do MST (Movimento dos Trabalhadores Rurais sem Terra), cuja pauta predominante era a luta pela não mecanização da produção e pela não construção de barragens.

${ }^{12}$ Movimento estudantil (liderado pela UNE e pela UBES) que reivindicava inicialmente o passe livre nos transportes públicos e a meia entrada em eventos, acabou se consolidando com o pedido e a consequente saída do poder do então Presidente Fernando Collor de Melo.
} 
(1992), a Passeata Gay em São Paulo ${ }^{13}$ ou Movimento do Passe Livre - MPL 14 (2003), a Operação Lava-Jato ${ }^{15}$ não atuaram ou não procedem assim, a crítica especializada, que emite suas opiniões em crônicas diárias, até mesmo por carência de fatos mais reais que surreais sobre arte, cultura, política e sociedade, tratava e ainda trata de inadvertidamente fazê-lo.

Em linhas gerais, a mídia e a intelligentsia atribuem a tais movimentos os moldes de representação ora de precursores geniais de uma vanguarda sabe-se lá de quê, ora o de responsáveis por retrocessos e por abalosalavanca de um movimento psíquico, sociológico, antropológico, político ou estético qualquer os o recolocam num cenário cult de adoração ou num papel demoníaco de rejeição.

Assim, a crítica midiática especializada em observações sociais, ao invés de melhorar a compreensão que o público precisa ter de seu próprio tempo, adensando as questões básicas originais, pasteuriza ou maquia os fatos. Noutros termos, via de regra, algo insignificante ou irrelevante (não que os movimentos citados sejam insignificantes ou irrelevantes), posto sob os holofotes dos apetrechos vocabulares da mídia e da intelligentsia entorpecida pela verdade irrefutável das próprias convicções fica mais colorido e palatável (DORFMAN \& MATTELART, 2007).

Neste sentido, então, é que, mais adiante, faremos algumas considerações que colocarão lado a lado da sociedade alguns dos movimentos socioculturais aludidos acima, com o intuito de demonstrar a maneira pela qual tais manifestações tomam para si os fatos sociais e culturais contemporâneos

\footnotetext{
${ }^{13}$ A parada do orgulho LGBT é realizada na Avenida Paulista, em São Paulo, desde 1997, entre os meses de maio e junho. Na edição de 2017, reuniu, segundo os organizadores do evento,19 Trios Elétricos e mais de três milhões de pessoas.

${ }^{14}$ Apesar do MPL ter ganho notoriedade mundial no ano de 2013, reportamos sua origem dez anos antes, em Salvador - BA. À época, houve ali intensa mobilização quanto ao preço das passagens no transporte público, o que levou a uma paralização de 10 dias da capital baiana. Em 2001, em Santa Catarina - SC, depois da chamada Revolta da Catraca, a cidade de Florianópolis parou por quase um mês. Fatos como esse eclodiram pelo país inteiro ao longo da última década e, em 2013, Estados brasileiros como São Paulo - SP, Rio de Janeiro - RJ e Minas Gerais - MG viveram dias de intensos protestos, passeatas e vandalismos. No início, as pessoas reivindicavam o passe livre e, com o passar dos dias, a pauta foi se ampliando, e as exigências chegaram à solicitação pelo fim da corrupção, a transparência nas contas públicas e a derrubada de Projetos de Lei (como o da proposta de PL 147) contrários à vontade popular.

15 Procedimento de investigação e de punição a corruptos no Brasil, iniciado em 2009, com desdobramentos amplamente noticiados pela imprensa nacional e estrangeira, dado aos efeitos que tem produzido.
} 
Volume 6, Ano IV, $2^{\circ}$-Semestre de 2018

transformando-os em representações alegóricas do status quo por meio de usos específicos da linguagem.

\section{DESENVOLVIMENTO}

A partir de agora, portanto, nos debruçamos sobre um debate, em que 0 perfil sociocultural de alguns dos movimentos e ativismos sociais serão revisitados.

Desse modo, iniciando aleatoriamente pela Bossa Nova (na grafia anterior à presente modalidade escrita, se escrevia Bossa-Nova, com hífen, embora hoje se admita as duas grafias, a antiga e a nova, adoto aqui a mais recente), vemos que esta manifestação sociocultural ou esta modalidade estética, como quisermos (CAMPOS, 1993) ${ }^{16}$, se tratava de um movimento genuíno, musical e linguisticamente significativo, cujo suporte principal de expressão priorizou o rigor musical, a palavra muitíssimo bem cantada e a norma padrão de linguagem escrita.

O movimento bossanovista, além de inovar o critério de composição e arranjos poéticos das letras e das harmonias da Música Popular Brasileira, teve, especialmente com o advento da genialidade de João Gilberto, a possibilidade de fazer retirar da Música Popular Brasileira o rótulo de manifestação cultural que é fruto de uma civilização subalterna ou exótica, apondo-a sob um carimbo de música de qualidade tipo exportação, ao mesmo tempo em que elevava qualitativamente o registro linguístico brasileiro a um patamar de excelência diferenciado na história cultural brasileira, uma vez que pôs o povo a cantarolar pelas ruas um repertório vocabular refinado e um conjunto de excelentes melodias.

Por outro lado, não é o mesmo fenômeno que ocorreu, por exemplo, com a performer musical portuguesa Maria do Carmo Miranda da Cunha, que se popularizou como a brasileira Carmem Miranda (apesar de nascida em Portugal, em 1909), pois ela foi "exportada" para os Estados Unidos e para o

\footnotetext{
${ }^{16}$ Sob a liderança de João Gilberto, Tom Jobim e Vinicius de Moraes, nasceu a Bossa Nova. Sob a influência do jazz norte-americano, filhos da classe média brasileira começaram a se expressar por meio de um repertório musical requintado e tipo exportação.
} 
mundo (entre 1930 e 1950) como figura de entretenimento de fácil degustação, a serviço de uma elite consumista e para a apreciação internacional do nosso exotismo étnico e cultural.

Isso se deu, mais ou menos sob os moldes do que ocorreu com 0 personagem de quadrinhos Zé Carioca ${ }^{17}$ :

Seria falso afirmar que Walt Disney es un mero comerciante. [...] Más allá de la cotización busrsátil, sus creaciones y símbolos se han transformado em una reserva incuestionable del acervo cultural del hombre contemporáneo: los personajes han sido incorporados a cada hogar, se cuelgan em cada pared, se abrazan en los plásticos y las almohadas, y a su vez ellos han retribuido invitando a los seres humanos a pertenecer a la gran família universal Disney, más allá de las fontreras y las ideologias, más acá de los odios y las diferencias y los dialectos. Con este passaporte se omiten las nacionalidades, y los personajes pasan a constituirse en el puente supranacional por médio del cual se comunican entre si los seres humanos. $Y$ entre tanto entusiasmo y dulzura, se nos nubla su marca de fábrica registrada. Disney, entonces, es parte - al parecer inmortalmente - de nuestra habitual representación colectiva (DORFMAN \& MATTELART, 1972 republicado em 2007, p. 11).

$\mathrm{Na}$ contramão disso, vê-se que a Bossa Nova entrou no mercado internacional via Carnegie Hall, em Nova York, num show realizado em1962. Enquanto isso, por sua vez, a Carmem Miranda subiu aos palcos estrangeiros em 1939, com um cacho de bananas na cabeça, desfilando, cantando e reiterando iconicamente nos trejeitos faciais e no rebolado do quadril a sensualidade, a estética da malandragem e o paradigma de um Brasil fornecedor ad aeternum de commodities, posição, aliás, a que se confina a América Latina como um todo até hoje.

Dez anos após o surgimento da Bossa Nova, um grupo de brasileiros, predominantemente formado por baianos, toma de assalto a Música Popular Brasileira. Gilberto Gil, Caetano Veloso, Tom Zé, Torquato Neto e Nana Caymmi indicam uma saída para o impasse de estagnação cultural tupiniquim:

\footnotetext{
${ }^{17}$ Inspirado num cartunista brasileiro, que se chamava José Carlos de Brito Cunha (conhecido por J. Carlos), o próprio Walt Disney desenhou e popularizou esse personagem - o Zé Carioca. A nota depreciativa sobre isso é que, no começo, o personagem Zé Carioca era uma homenagem ao talento do artista brasileiro e, lentamente, o desenho animado se tornou uma espécie de "embaixador" de um estereótipo que associava o Brasil e o povo brasileiro ao samba, à cachaça, ao carnaval, à preguiça, à festa e à vagabundagem.
} 


\section{Volume 6, Ano IV, $2^{\circ}$ Semestre de 2018}

habemus a Tropicália. Augusto de Campos (1993), o mesmo que batizara o movimento concretista, lembra que, para fazer frente ao mau gosto do iê-iê-iê brasileiro, a essência deveria prevalecer sobre certas aparências.

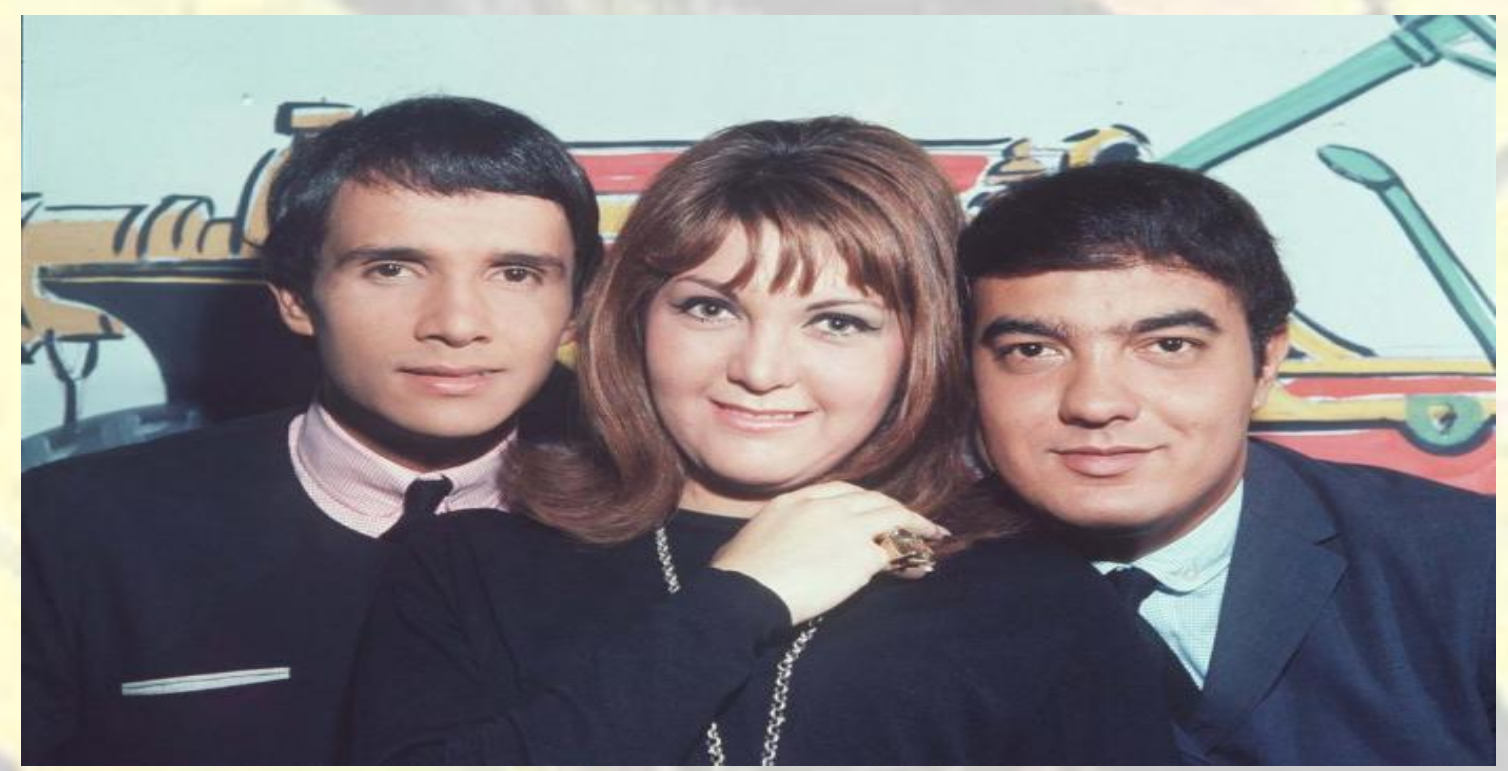

Roberto Carlos, Erasmo Carlos e a cantora Wanderléa comandavam o Programa Jovem Guarda, aos domingos na TV Record, influenciando gerações desde 22/08/1965.

Isto é, haveríamos de retornar, lamentavelmente, ao sambão gritado, quadrado, cuja representação coletiva fora sintetizada pela Carmem Miranda e pelo Zé Carioca, reificada pelo iê-iê-iê brasileiro importado dos Estados Unidos via integrantes da Jovem Guarda.

Diante do balanço financeiro dos festivais de música da Record, continua Campos (1993), os produtores culturais abriram os olhos: como haviam perdido dinheiro até então, o que rendia mesmo era a velha batucada. Assim, o bailão do mau gosto que, de alguma forma, foi reeditado pela inexpressividade do Festival de Música Popular realizado no ano 2000 pela Rede Globo de Televisão, faz algum sentido, especialmente se este desastre for projetado sobre o que se convencionou chamar no Brasil de "sertanejo universitário" e seus congêneres ${ }^{18}$.

\footnotetext{
${ }^{18}$ Nada contra a música sertaneja. O importante é que a música seja boa, esteja onde estiver. Contudo, no início dos anos 90, apesar de terem acrescentado aos tradicionais acordeões e violões, guitarras elétricas e sintetizadores (mais ou menos como fizeram os tropicalistas), a juventude dos cantores sertanejos que atualmente começam a fazer sucesso muito prematuramente, a irreverência das letras (duplos sentidos,
} 


\section{Volume 6, Ano IV, $2^{\circ}$ Sermestre de 2018}

Nesse Festival ainda, vale lembrar, novamente marcou presença Caetano Veloso (VELOSO, 2017). Num instante, sua "afilhada" artística, Virgínia Rodrigues, dotada de uma voz belíssima, entoava a raiz musical brasileira num canto "Olodum melismático medieval" ${ }^{19}$. Noutro instante, o ícone e um dos maiores expoentes dos antigos festivais, Caetano Veloso, faz a anticelebração do que poderia ter sido a retomada do glamour dos grandes festivais e de seus happenings. Cantando a letra de "Trilhos Urbanos", Caetano Veloso fez mais do que protestar. Selou, com seu poema-canção, o fim do que nem deveria ter começado. Denunciou, por meio da palavra cantada, a distância em que aquela avacalhação de festival da Rede Globo estava de qualquer festival do passado: "o melhor o tempo esconde / longe muito longe" ("Trilhos Urbanos", de Caetano Veloso: Cinema Transcendental, 1979, e Caetano Veloso, 1986).

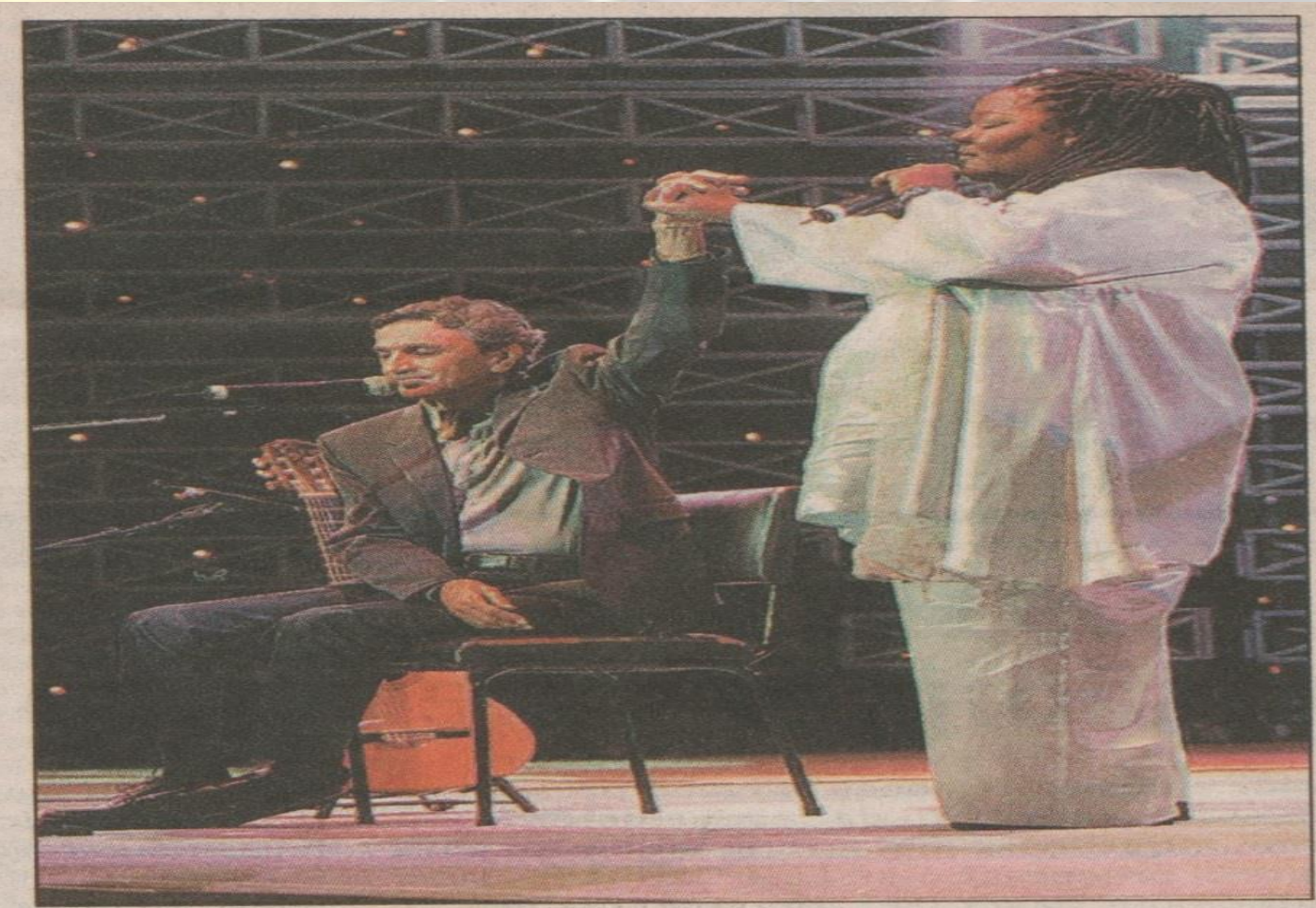

CAETANO E VIRGÍNIA Rodrigues: show de encerramento

alusões sexuais e desarranjos amorosos), a mistura de estilos e ritmos (juntando-se todos os ritmos e estilos, chega-se a nenhum) e a simplicidade dos arranjos harmônicos estão muito distantes de colocar o movimento dos musicais sertanejos universitários, como os do Axé Universitário, os do Brega Universitário, os do Forró Universitário etc. como representantes do que é do que pode a nossa língua portuguesa, a nossa música, a nossa sociedade e a nossa cultura.

19 Aqui, criei uma alegoria que reúne o canto folclórico e o canto religioso, misturando, consequentemente, o sagrado e o profano. 
Com esse procedimento, Caetano fez o que era próprio do Tropicalismo, isto é, fiat lux:

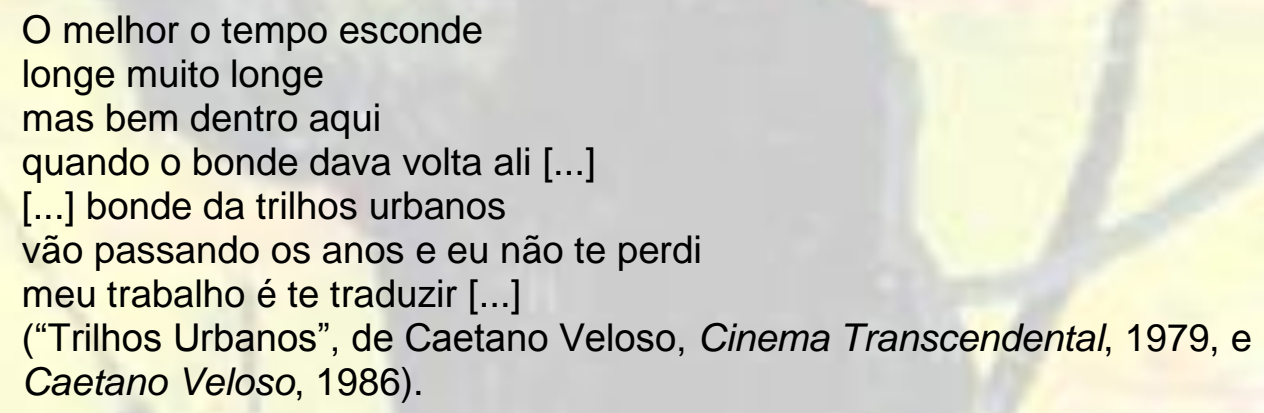

Segundo Campos (1993), o processo - a depreensão do caráter e de uma pretensa identidade nacional via observação das representações da cultura de massa - é bem fácil de ser entendido sob o ponto de vista dos estudos do mass media. A linguagem da música popular, argumenta Campos, é cultura de massa, e opera, portanto, na faixa da comunicação persuasiva, pretendendo convencer o ouvinte com base naquilo que ele já conhece, deseja e quer ouvir: isso dá, então, a tônica da validade que atribuímos à Carmem Miranda, ao Zé Carioca, à Jovem Guarda, ao Sertanejo Universitário, e também ao Movimento do Passe Livre, ao MST, à passeata do orgulho gay na avenida paulista etc.

Nessa mesma linha de explicações, encontramos o pensamento de Umberto Eco (2013) apontando que, desse mesmo modelo de convencimento do consumidor ressaltado por Campos (1993), resultaria uma espécie de confirmação do ouvinte quanto à validade das suas opiniões e convenções por intermédio da linguagem utilizada pelos operadores do sistema midiático contemporâneo.

Os tropicalistas, os estudantes, os trabalhadores rurais, cada um a seu tempo, tiveram aguda percepção, ainda que operando na faixa da inconsciência disso tudo, da crise de identidade e de participação política que se vivia no país. Quando o artista, como representante legítimo do povo, sente esse caráter duplo de crise, lembra Eco (2013), parece perceber existir uma correlação entre o sistema que organiza a tonalidade dos sons da música e a 
Volume 6, Ano IV, $2^{\circ}$ Semestre de 2018

psique dos indivíduos (o que viabilizaria a já aludida justificação dos ouvintes em suas expectativas com relação à produção de música e de cultura em geral), o que, segundo Eco, também permite verificar como produto da percepção dessa correlação um retorno instantâneo ao mundo moral, ideológico e social da coletividade a ser representada:

Perguntamos, então: como impingir a esses escritores a desqualificação de alienados da realidade social, se eles estão colocando em crise justamente os esquemas simplistas e a ingenuidade encolhida daquilo que os parâmetros consensuais da cultura denominam realidade? Como chamá-los de elitistas, se estão resgatando para todo um continente a força de uma esfera cultural até então esmagada? E, se a imensa maioria de nossa população não tem acesso ou não está sendo capaz de ler e de compreender essas criações, não reside justamente aí a grande força revolucionária dessas produções? (SANTAELLA, 1990, p. 62).

As performances tropicalistas e bossanovistas e as suas respectivas propostas harmônicas e poéticas parecem negar mesmo as regras linguísticas e tonais do fazer musical corrente. Sobre essa subversão, Eco (2013) é taxativo em afirmar que, agindo assim, o músico nega o sistema tonal não somente porque nele se sente alienado ao convencional. Mas nega-o porquê, negando, não apenas nega a estrutura desse sistema, como também nega a moral de uma ética social e teórica expressa por aquele sistema. No momento em que rompe com o sistema de difusão de informação, conclui Eco, o artista subtrai-se às condições normais de comunicação e parece agir em sentido antihumano, ou seja, à contramão do consenso sociocultural que baliza o homem médio.

No entendimento de Santaella (1990), entretanto, percebe-se que esse artista ou ativista sociocultural que nega o sistema não age contra o senso humano. Mas, pelo contrário e antes de tudo, age em favor dele. Os participantes das passeatas deste ou daquele tempo, isto é, contra a Ditadura, a favor do orgulho gay, em apoio ao juiz Sérgio Moro e à Lava-Jata etc., podem, então, mesmo que sem querer, agir favoravelmente em sentido contrário àquilo que pretendiam defender. 


\section{Volume 6, Ano IV, $2^{\circ}$ Semestre de 2018}

O fato de haver a incompreensão de suas obras ou de seus propósitos por parte de determinadas alas da sociedade não quer dizer que seus atos não sejam subversivos ou mesmo cooptados pela hegemonia de uma prática sociocultural dominante, uma vez que surgem dentro de um sistema cultural e identitário em crise contínua, como, aliás, é o caso do contexto brasileiro, em que o rótulo de cultura de alienados se não nos cabe, cabe-nos, ao contrário, mais o de revolucionários?

\section{RESULTADOS}

Entendemos, sinteticamente, que Caetano Veloso, principal líder do movimento tropicalista, enquadra-se melhor no contexto de subversão do sistema tonal e das linguagens verbais, audiovisuais, do que no paradigma do indivíduo revolucionário (segundo nos disse o próprio Caetano Veloso, em entrevista exclusiva ainda não publicada). Autor de vasta obra parece ter tornado o conteúdo de sua obra espelho do seu agir e do seu modo particular de ver o mundo e de julgá-lo, traduzindo-o em um modelo específico de formar as ideias e de torná-las relevantes diante da relação da arte com o mundo sociocultural, articulando essas necessidades ou preocupações dentro do Tropicalismo.

O Tropicalismo, por sua vez, representou a abertura de uma etapa nova para a cultura brasileira via Música Popular Brasileira. Essa etapa se sustentou na base de um levantamento do comportamento e da tradição viva nas vilas e favelas, nas salas de reunião e nos escritórios empresariais, na recriação dos elementos folclóricos herdados das culturas geradoras da cultura brasileira. Representou também a possibilidade da insurgência e do enfrentamento ao establishment, prática, diga-se en passant, bem afeita a movimentos como o MST, o Passe Livre, a Passeata dos Cem Mil, a Parada do Orgulha LGBT e os Caras-Pintadas etc.

Eco (2013) diz que o sistema de linguagem recusado pelo artista de vanguarda e consequentemente reativado pela militância sociocultural encontra-se desapossado das coordenadas da velha ordem, tal como está despojado das diretrizes canônicas do sistema de linguagem que adota em sua 


\section{Volume 6, Ano IV, $2^{\circ}$ Semestre de 2018}

poética. Os estilos musicais ditos universitários reverberam essa práxis. Essa mesma dupla e velha ordem encontra reminiscências nos sistemas esclerosados dos dogmas dirigistas, aludidos anteriormente por Santaella (1990).

Nesse sentido, acentua Eco (2013), é que o protagonismo sociocultural protesta quanto às formas tradicionais e mais bem aceitas de produção cultural - o sambão quadrado e gritado é só exemplo, é apenas sintoma -, sem anulálo nessa rejeição, mas agindo no interior dele.

Essa relação com o contexto social não ocorre, portanto, por afinidade, mas por apagamento imaginário da distância entre o sistema político ou esteticamente orientado. Para o desentorpecimento da visão e do código social organizado, é necessário agir politicamente para fazer dar certo tudo que está acomodado e engessado sob os moldes da tendência hegemônica. É assim que os operadores da Lava-Jato, por exemplo, têm agido em nossas estruturas, mesmo sem sabê-lo.

Não alienados da relação do protagonista social com os aspectos patrimoniais da cultura brasileira, os brasileiros fizeram e ainda fazem revelar através de suas atitudes a identidade da sociedade brasileira híbrida e em formação que era e ainda é gritada pelas ruas, por meio de vozes que saíam, e continuam saindo, de bocas banguelas, num grito de gol ou num sussurro sob tortura, ou num êxtase cerimonial místico, ou numa passeata pelo passe livre, pelo impeachment de presidentes, ou por melhor qualidade na saúde pública.

\section{CONCLUSÕES}

Em sucinto resumo das ideias expostas, vistas aqui sob a ótica antropofágica, por exemplo, verificamos que o que se chamou de Antropofagia era um conjunto de procedimentos artísticos, mas também políticos, por meio dos quais se objetivava "deglutir" do repertório sociocultural disponível o que, para a época do advento do Modernismo no Brasil, era moderno e desenvolvido ou simplesmente estrangeiro, para depois fazê-lo retornar, 


\section{Volume 6, Ano IV, $2^{\circ}$ Semestre de 2018}

revestindo-o com o nosso subdesenvolvimento tecnológico e com os nossos arcaísmos impregnados no país desde o colonialismo.

Nós, brasileiros, assim, somos frutos da assimilação histórica que uniu num mesmo corpo o belo e o feio, transformando-nos numa nação barroca da renascença, a partir da iluminação de movimentos como a Bossa Nova, a Tropicália, o MST, o Passe Livre, os recentes estilos universitários, a passeata do orgulho gay, a Operação Lava-Jato etc. Somos, por isso, maravilhosamente terríveis por sermos social e culturalmente negros, índios, eruditos, populares, pobres, ricos, honestos e corruptos, homens e mulheres e também europeus paradoxalmente afrodescendentes assimilados e pós-modernos.

Ou seja, para sabermos mais sobre o que somos devemos considerar o que os tipos interferentes na nossa mistura étnica e cultural nos proporcionaram, e de que maneira contribuíram para a imagem que vemos ao olharmo-nos no espelho. Procedendo dessa maneira verificaremos qual o tipo de assimilação fizemos derivar desse processo, como se deu em nós a prática miscigenatória. Um bom lugar para lançarmos nosso olhar investigativo, sem dúvida, é o interior dos movimentos sociais ou nas expressões sociais de vanguarda brasileiros, tais como os aventados neste texto.

Schwarz (2008) parece lançar seu olhar nessa direção, ao dizer que a imagem tropicalista (e, por extensão, o Cinema Novo, a Bossa-Nova, a parada do orgulho gay etc.) seria capaz de encerrar em si o passado (nesse passado caberiam a estrutura rural colonial e a miscigenação para serem assimilados no processo evolutivo e de construção de nossa identidade) na forma de males ativos ou ressuscitáveis, e que também seria capaz de sugerir, como se a arte ou a mídia possuíssem um poder de predição oracular, o que ainda parece ser o nosso destino (como processo contínuo), e que seria essa a razão pela qual nós ainda não nos cansamos de olhá-las (porque o desenho que vemos é o resultado parcial da prática da assimilação e nos compadecemos narcisicamente nessa ou naquela modalidade de representação).

Perguntamo-nos, então, que tipo de estímulo - visual, intelectual, ético, estético, político - recebeu Schwarz para estabelecer o que seria ou que conteúdo teria essa imagem poderosa e perpetuadora do horizonte sociocultural brasileiro da qual nos fala, pois parece que essa imagem, da 


\section{Volume 6, Ano IV, $2^{\circ}$ Semestre de 2018}

maneira como ele nos diz, é capaz de representar bem a função assimiladora que, a nosso ver, caracteriza nossa identidade, nossa cultura e todos os seus movimentos e ativismos socioculturais.

Os elementos novos e velhos de nossa linguagem social de viver concorrem para a justaposição do universo da técnica ao universo do retrógrado no processo de assimilação. A imagem síntese sociocultural brasileira, entendida como coisa exótica e aberrante no passado e, hoje, a recolocação internacional do Brasil como país emergente, não melhorou nosso status quo. Pelo contrário, denunciou e ainda denuncia o atraso do país em todos os setores da produção, dos serviços básicos à população ou da falta crônica de infraestrutura.

As comparações entre o internacional e o nacional proporcionadas pelo Tropicalismo, pelo MST, pelo Cinema Novo, pelo Passe Livre, pela Lava-Jato, pelo orgulho gay evidenciam, num contraponto com o pensamento de Schwarz, o estado simultâneo de "riqueza e de pobreza nacional" - que reúne todos os nossos extremos que oscilam entre o vanguardismo e o atraso -, e fornece um parâmetro para dimensionar o coeficiente da infelicidade estética e grotesca à qual se confina a identidade contemporânea nacional.

Wisnik (1995) ressalta que o otimismo da Bossa Nova devia ser entendido como exigência de superação (o que entendemos aqui como etapa final da assimilação) e seu complementar, em forma de pessimismo. Esses extremos foram presentificados pela Tropicália, pela Lava-Jato, pelo sertanejo universitário, que revelaram não o resultado, o produto final da assimilação, mas o processo pelo qual se dá a assimilação na história cultural da civilização brasileira.

Essa relação dialética na cultura brasileira é similar ao procedimento antropofágico. Assim, percebemos que o Brasil moderno é uma resultante paradoxal - uma nação barroca da renascença. Obscura e iluminada.

Vemos nessa resultante atualizada uma juventude alienada, que pinta a cara com as tintas do engajamento do nosso ontem, mas que, contudo, agem apenas como mímicos do passado-sambão-quadrado universitário contemporâneo midiatizado. Percebemos que nesse ritual de transmutação 


\section{Volume 6, Ano IV, $2^{\circ}$ Semestre de 2018}

praticado por brancos, por índios, por brasileiros enfim, por exemplo, que nas tintas da face, há uma celebração do paradoxo de similitude entre o Brasil modernista e o Brasil moderno: o modernista absorve o índio e o reelabora, o moderno o extingue. $\mathrm{O}$ contemporâneo o coloca numa vitrine.

Embora possamos perceber que os brasileiros do passado e do presente possam estar, de fato, uns à procura dos outros, notamos que o processo de assimilação foi invertido: quando estes dois tempos se encontrarem, se destruirão, devido ao medo recíproco midiaticamente retroalimentado, ao invés de se "devorarem". Em suma, vê-se no dia a dia, que o branco procura um índio tecnológico, e o índio procura um branco naturalista: caminham na mesma direção uns dos outros, mas nunca se encontram. Essa é a cara do Brasil: um caminho ainda, mas já repleto de desencontros. 


\section{Volume 6, Ano IV, $2^{\circ}$ Semestre de 2018}

\section{REFERÊNCIAS}

CAMPOS, Augusto. Balanço da Bossa e Outras Bossas. São Paulo: Perspectiva, 1993.

CHAUÍ, Marilena. Conformismo e Resistência. São Paulo: Autêntica, 2017.

DORFMAN, Ariel. \& MATTELART, Armand. Para Leer al Pato Donald comunicación de masa y colonialismo. España: Siglo XXI de España Editores S/A, 2007.

ECO, U. Do modo de Formar como Engajamento para com a Realidade. In: . ECO, U. Obra Aberta. São Paulo, Perspectiva, 2013, p. 227-62.

SANTAELLA, Lúcia. Arte e Cultura - equívocos do elitismo. São Paulo: Cortez, 1990.

SCHWARZ, R. O Pai de Família e outros estudos. São Paulo: Cia. Das Letras, 2008.

VELOSO, Caetano. Verdade Tropical. São Paulo: Cia das Letras, 2017 (ed. Comemorativa de 20 anos da obra).

WISNIK, José Miguel. La gaya ciencia: Literatura y musica popular en Brasil. Revista de Ocidente, no 174. Madri, 1995. 